collected and analysed for amino-acid content (Table 1) by a quantitative paper chromatography technique using the spot-area method ${ }^{3}$. For comparative purposes a column of a synthetic zeolite was prepared and used under identical conditions.

Since in any column operation there is a limited adsorption time, the relative adsorption-rates of aspartic acid and glycine for both natural and synthetic samples of the solids used in the column experiments were assessed by means of static experimonts. In these experiments 1-gm. samples $(-200$ B.S.S. mesh) were placed in $100 \mathrm{ml}$. of an aminoacid solution containing $5 \mathrm{mgm}$. of each of the above two acids. After intermittent shaking for an average period of six days, 25-ml. aliquots were removed and their amino-acid contents determined chromatographically (Table 2). A sample of synthetic barium chromate was used as an additional adsorbent.

\begin{tabular}{|c|c|c|c|}
\hline \multirow{2}{*}{ Adsorbent } & \multirow{2}{*}{ Type } & \multicolumn{2}{|c|}{$\begin{array}{c}\text { Amino-acid adsorbed } \\
\text { (mgm. per gm. adsorbent) }\end{array}$} \\
\hline & & Aspartir acid & Glycine \\
\hline Zinc sulphide & $\begin{array}{l}\text { Natural } \\
\text { Synthetic }\end{array}$ & $1.96 *$ & $\begin{array}{l}1.80 \\
0.44 \\
\end{array}$ \\
\hline Lead sulphide & $\begin{array}{l}\text { Natural } \\
\text { Synthetic }\end{array}$ & -0.76 & $\begin{array}{l}0.61 \\
0.12\end{array}$ \\
\hline Lead manganate & $\begin{array}{l}\text { Natural } \\
\text { Synthetic }\end{array}$ & $\begin{array}{l}0.84 \\
0.08\end{array}$ & $\begin{array}{l}0.64 \\
0.00\end{array}$ \\
\hline Lead sulphate & $\begin{array}{l}\text { Natural } \\
\text { Synthetic }\end{array}$ & 0.28 & 0.08 \\
\hline Barium sulphate & $\begin{array}{l}\text { Natural } \\
\text { Synthetic }\end{array}$ & $\overline{0.00}^{*}$ & $\begin{array}{l}0.44 \\
0.00\end{array}$ \\
\hline Lead chrnmate & $\begin{array}{l}\text { Natural } \\
\text { Synthetic } \\
\text { Fused }\end{array}$ & $\begin{array}{l}0 \cdot 60 \\
0.40 \\
0 \cdot 84\end{array}$ & $\begin{array}{l}0 \cdot 52 \\
0 \cdot 00 \\
0 \cdot 40\end{array}$ \\
\hline Barium chromate & Synthetic & $1 \cdot 20$ & 0.51 \\
\hline Zeolite & Synthetic & $5 \cdot 00$ & $5 \cdot 00$ \\
\hline
\end{tabular}

From an inspection of Table 1 it can be seen that in all cases (except lead sulphate). the adsorption of aspartic acid was greater than or approximately equal to that of glycine. This observation has been confirmed by the results of the static experiments (Table 2), which show that the amounts of aspartic acid adsorbed on both natural and synthetic solids are decidedly greater than the corresponding amounts of adsorbed glycine. Table 2 also shows that in all available comparisons between natural and synthetic solids, the former exhibited higher adsorptive capacities for both amino-acids.

A study of the mechanism of the process of aminoacid adsorption on sparingly soluble inorganic solids and an attempted correlation between adsorptive capacity and the electrokinetic properties of the adsorbents have been made. An account of such results will be presented in a later publication.

Chemistry Department,

D. J. O'CONNOR

University of Melbourne.

Research Laboratory, Prestige, Ltd.,

Melbourne.

'Buchanan, A. S., and Heymann, E., Nature, 161, 649 (1948); Proc. Roy. Soc., A., 195, 150 (1948). 'O'Connor, D. J., and I3uchanan, A. (unpublished data).

Hamoir, 7 C. M. Biochem, $I, 39,485$ (1945).

' Bryant, F., and O'Connor, L. J., Aust. J. Sci., 13, 111 (1951).

\section{F. BRYANT}

\section{Deposition of Metal Films on Jelly-like Materials}

SUBSTANCES based on gelatine or agar-agar are used extensively for making moulds, from which replicas can then be made. In order to use the process of electroforming in conjunction with such jelly-moulds, it is necessary to provide the mould surface with a conductive layer. As agar composition, for example, contains about 95 per cent water, it is obvious that the moulds cannot be submitted to drying without causing deformation, and the usual method of coating moulds with aqueous colloidal graphite is therefore inapplicable.

Probably because of the high water-content of the jelly material, it was found to be impossible to produce films by silver-mirror techniques. The metallization by dry metal dust (for example, bronze powder) was rejected as not likely to yield sufficiently accurate reproduction. I have employed various impregnation techniques ${ }^{1}$ which are now sufficiently improved to warrant trials in various fields of application.

The surface of the jelly is treated with aqueous silver-ammonio-nitrate made in the usual way. (Note : This preparation, which is widely used by dentists for impregnating natural teeth, is reported to be liable to become explosive. It is inadvisable to store large amounts, and the spent liquid should never be allowed to form crusts or to $\mathrm{dry}^{2}$.) The liquid is completely evaporated by a jet of compressed air, but a sufficient amount of silver salt is left behind on the surface of the jelly. Instead of exposing this now to gaseous hydrogen sulphide (the resulting silver sulphide is brittle, unstable in acid solutions, and will not adhere to the jelly), the impregnated mould is exposed to red selenium, which is dissolved, for example, in carbon disulphide. Immersion in this solution for one to twenty minutes will produce a film of metallic appearance which probably consists of silver or silver selenide. It is transparent to light, conducts an electric current, but may float off when immersed. in aqueous media. The film is obviously situated on the surface of the water-soluble silver salt, which was previously left by evaporation on the surface of the jelly. It is sufficiently stable to act as protection for the remainder of the salt, which can now be reduced to metallic silver, trapped as it is between the jelly and the silver selenium film. Suitable reducing media are some photographic developer's, hypophosphorous acid (10 per cent), hydrazinehydrate, etc., in which the treated mould will quickly. be covered with a dense opaque film of high conductivity on which electrodeposition may be carried out. As an alternative, nascent hydrogen can be employed, which is evolved at the surface of the mould by making this the cathode in a cell containing acidified water. Apparently the conductivity of the initial silver (or silver selenium) layer is sufficient. for this purpose, and soon the bulk of the silver salt. is reduced to a dense metallic film.

Dental School,

King's College Hospital Medical School, (University of London), London, S.E.5. June 10.

${ }^{1}$ Rosenstiel, E., Dental Record, 70, 105 (1950).

${ }^{2}$ Upton, P. B., J. Electrodep. Tech. Soc., 22, 45 (1947). 